\title{
Diversidade sexual e de gênero na escola: revisando discussões no Ensino de Ciências
}

\author{
Sexual and gender diversity in school: a Science Teaching discussion \\ review
}

\section{Diversidad sexual y de género en la escuela: una revision de las discusiones en la Enseñanza de las Ciencias}

Bruna Peres Viana ${ }^{1}$; Bruno Pastoriza ${ }^{1}$

\section{RESUMO}

Assumindo a complexidade do debate de temas ligados a diversidade sexual e de gênero na escola, o presente texto se propõe a analisar os encaminhamentos e posicionamentos a respeito de gênero e sexualidade nas produções da área de Ensino de Ciências disponíveis no Portal de Periódicos da CAPES. O processo analíticometodológico foi a Análise Textual Discursiva (ATD). Esta possibilitou a criação de 4 categorias, que apontam as reiteradas discussões sobre gênero e sexualidade centradas num viés biológico, as adversidades existentes no ensino da diversidade sexual e de gênero, a relação entre sexismo e educação e as relações entre discurso e poder que articulam essa temática na escola. Constatou-se que a presença de discriminação e preconceito são baseados em princípios sexistas e patriarcais, originados e apoiados em relações de poder que moldam e regram a historicidade, a cultura e a sociedade.

Palavras-chave: Diversidade; Ensino; Gênero; Sexualidade.

\begin{abstract}
Assuming the complexity of the debate on issues related to sexual and gender diversity at school, this text proposes to analyze the directions and positions regarding gender and sexuality in the productions in the area of Science Education available on the CAPES Journal Portal. The analytical-methodological process was the Textual Discourse Analysis (TDA). This enabled the creation of 4 categories, which point to the repeated discussions about gender and sexuality centered on a biological bias, the adversities existing in the teaching of sexual and gender diversity, the relationship between sexism and education and the relations between discourse and power that articulate this thematic at school. It was found that the presence of discrimination and prejudice are based on sexist and patriarchal principles, originated and supported in power relations that shape and rule historicity, culture and society.
\end{abstract}

Keywords: Diversity; Teaching; Gender; Sexuality.

\section{RESUMEN}

Asumiendo la complejidad del debate sobre temas relacionados con la diversidad sexual y de género en la escuela, este texto tiene como objetivo analizar las direcciones y posiciones con respecto al género y la sexualidad en las producciones en el área de Educación Científica disponibles en el Portal de la revista CAPES. El proceso analítico-metodológico fue el Análisis del Discurso Textual (ADT). Esto permitió la creación de 4 categorías, que apuntan a las repetidas discusiones sobre género y sexualidad centradas en un sesgo biológico,

\footnotetext{
${ }^{1}$ UFPel - Universidade Federal de Pelotas, Pelotas/RS - Brasil.
} 
las adversidades existentes en la enseñanza de la diversidad sexual y de género, la relación entre sexismo y educación y las relaciones entre discurso y poder que articulan esto temática en la escuela. Se descubrió que la presencia de discriminación y prejuicio se basa en principios sexistas y patriarcales, originados y respaldados en relaciones de poder que dan forma y rigen la historicidad, la cultura y la sociedad.

Palabras clave: Diversidad; Enseñanza; Género; Sexualidad.

\section{INTRODUÇÃO}

Este trabalho se propõe a discutir sobre a temática de Diversidade Sexual e de Gênero na escola, voltada, mais especificamente, para a análise da prática docente e a formação de professores e professoras de Ciências da Natureza para a Educação Básica. Tem como objetivo analisar os discursos sobre a temática Diversidade Sexual e de Gênero na Educação Básica no campo do Ensino de Ciências da Natureza em produções acadêmicas.

A falta de discussões e materiais de apoio ao ensino e à aprendizagem, bem como a carência de discussões sobre a temática Diversidade Sexual e de Gênero durante minha trajetória acadêmica, fizeram com que a importância de manifestos e debates sobre o tema para a educação se tornassem minha área de pesquisa. Como professora licenciada em Ciências Biológicas, procuro conhecer as curiosidades e dúvidas dos alunos e das alunas, buscando explicar informações pouco conhecidas ou retificar as equivocadas do ponto de vista educacional, visando o aprimoramento da educação científica e social.

Discutir informações relacionadas à Diversidade Sexual e de Gênero é um exercício de analisar diferentes aspectos da sociedade em termos daquilo que se fala, produz, organiza e de como tais elementos são gestados. Tal discussão também se mostra dependente de fatores como a cultura e o momento histórico no qual a sociedade está inserida, a maneira como se pensa sobre um assunto e como seus significados se apresentam em termos de sua realidade existencial. Para Louro,

É necessário demonstrar que não são propriamente as características sexuais, mas é a forma como essas características são representadas ou valorizadas, aquilo que se diz ou se pensa sobre elas que vai construir, efetivamente, o que é feminino ou masculino em uma dada sociedade e em um dado momento histórico (LOURO, 2003, p. 21).

A heteronormatividade e o viés biológico que se apresentam as temáticas na escola é uma questão complexa, pois carrega posicionamentos, por vezes, discriminatórios e preconceituosos, reproduzidos no próprio ambiente escolar (LOURO, 2003). Uma forma conveniente para se evitar a marginalização de grupos sociais e culturais é questionar seus próprios posicionamentos, crenças e ideias como professor e professora. Para Junqueira (2009, p. 178), visibilizar a diversidade no processo educacional

[...] pressupõe o empenho em desestabilizar qualquer pretensão, ressentimento, intolerância ou ódio alimentados pelo "narcisismo das pequenas diferenças". Requer, portanto, o desenvolvimento de uma postura de abertura em relação ao "outro": de acolhimento, de reconhecimento da diferença como legítima e de rediscussão acerca dos processos que a produzem e dos mecanismos de distinção e hierarquização entre os sujeitos, tendo em vista que o reconhecimento da diferença 
é "um ponto de partida de um longo e talvez tortuoso processo político, mas no limite benéfico.

A divulgação de informações com base em pesquisas acadêmicas e científicas sobre Diversidade Sexual e de Gênero para docentes, que atuam na área da educação, ou ainda em formação, pode cientificar e evitar expressões e ações de cunho discriminatório, promovendo um ambiente profissional e social mais respeitoso a partir do conhecimento e da visibilidade.

A partir dessas ideias e da problematização dessa temática, o processo metodológico empregado nesta pesquisa foi a Análise Textual Discursiva (MORAES; GALIAZZI, 2006), aplicada em artigos com temática de diversidade sexual e de gênero no ensino de ciências.

Estas transcrições apontaram a biologia como base exclusiva para educação de gênero e sexualidade, expondo, também, as intervenções familiares e socialmente conservadoristas quanto ao assunto na instituição de ensino. Também possibilitaram problematizar o sexismo como motivação da apreensão de se falar sobre o tema em sala de aula, analisando os discursos e as relações de poder existentes na escola e, por vezes, produzidos por ela. Ao analisar tais resultados, eles nos permitem (re)pensar nossos cursos de formação de professores e nossas ações docentes, visibilizando um processo educativo mais inclusivo, respeitoso e informado - algo desejado a uma educação para a cidadania.

\section{METODOLOGIA}

Em relação a estratégia de análise, este trabalho será direcionado a um delineamento empírico com base em análise qualitativa e documental dos dados, que, segundo Lüdke e André (1986, p. 38), "a análise documental pode se constituir numa técnica valiosa de abordagem de dados qualitativos seja complementando as informações obtidas por outras técnicas, seja desvelando aspectos novos de um tema ou problema".

O trabalho analítico-metodológico segue as orientações da Análise Textual Discursiva (ATD), que tem como fundamento, no exercício da escrita, a mediação na elaboração de significados, em que o pesquisador realiza um movimento intenso de interpretação e produção de argumentos (MORAES; GALIAZZI, 2006).

Esta tipologia de pesquisa se inicia em um processo chamado unitarização, na qual os materiais coletados são selecionados e divididos em unidades de significado. Neste trabalho, cada uma das unidades foi codificada, sendo esse código citado ao longo do texto. Logo após a realização da unitarização, inicia-se o processo de categorização, em que são articuladas as unidades de significado semelhantes. Então, tal método possibilita a construção de metatextos analíticos que irão instituir os textos interpretativos, exemplo deste próprio artigo. Neste trabalho, as unidades foram selecionadas como trechos retirados dos textos escolhidos, e, a partir destes, foram observadas diferentes interpretações de significados que resultaram em comentários acerca dos fragmentos. Tais unidades serão citadas com a codificação 'U', seguida pelo número arábico correspondente a unidade, conforme ordenada no texto; logo após, uma letra maiúscula representa o texto em que foi encontrada a unidade; ao fim, a categoria onde situa-se a unidade será codificada por um algarismo romano.

Para a construção das discussões deste trabalho foram utilizados artigos resultantes de uma busca no Portal de Periódicos da CAPES. Foram encontrados 8.439 documentos referentes aos termos de busca: gênero educação ciências, orientação sexual educação ciências, sexualidade educação 
ciências, identidade gênero educação ciências, em uma investigação desenvolvida no segundo semestre de 2018. Todos os textos foram refinados com vistas aos resultados incluírem apenas artigos revisados por pares, com data de publicação entre os anos 2000 a 2018. Após o refinamento foi possível obter 12 textos que apresentavam conteúdo referente tanto aos termos utilizados para a pesquisa, quanto à linha temática da investigação, que se volta ao Ensino de Ciências da Natureza no contexto escolarizado (tabela 1).

Tabela 1: textos utilizados na análise e obtidos após processo de refinamento da busca.

\begin{tabular}{|c|c|c|c|}
\hline Revista & Autor & Título & $\begin{array}{c}\text { Ano de } \\
\text { publicação }\end{array}$ \\
\hline $\begin{array}{l}\text { Research, Society and } \\
\text { Development }\end{array}$ & $\begin{array}{l}\text { Santana, J.; } \\
\text { Santos, V. }\end{array}$ & $\begin{array}{l}\text { A inserção de conteúdos sobre identidade de } \\
\text { gênero na escola: Uma visão a partir de } \\
\text { noções sobre conhecimento/saberes }\end{array}$ & 2018 \\
\hline $\begin{array}{l}\text { Revista Tecné, Episteme y } \\
\text { Didaxis: TED }\end{array}$ & Souza, M. & $\begin{array}{l}\text { Partilhando uma experiência de ensino sobre } \\
\text { gênero e sexualidade em um curso de } \\
\text { formação de professores de } \\
\text { Ciências e Biologia }\end{array}$ & 2014 \\
\hline $\begin{array}{l}\text { Revista on line de Política } \\
\text { e Gestão Educacional }\end{array}$ & Pessoa, E. & $\begin{array}{l}\text { Políticas Públicas, a atuação docente e o } \\
\text { desenvolvimento de habilidades: gênero e } \\
\text { sexualidades na educação básica }\end{array}$ & 2012 \\
\hline Revista Exitus & $\begin{array}{l}\text { Martines, E.; } \\
\text { Rossarolla, J. }\end{array}$ & $\begin{array}{l}\text { Sexo e sexualidade: tabu, polêmica ou } \\
\text { conceitos polissêmicos? Reflexões sobre/para } \\
\text { a formação de educadores }\end{array}$ & 2018 \\
\hline Rev. Ensaio & $\begin{array}{l}\text { Martins, E.; } \\
\text { Hoffmann, Z. }\end{array}$ & $\begin{array}{l}\text { Os Papéis de gênero nos Livros Didáticos de } \\
\text { Ciências }\end{array}$ & 2007 \\
\hline Psicologia \& Sociedade & $\begin{array}{l}\text { Tonatto, S.; } \\
\text { Sapiro, C. }\end{array}$ & $\begin{array}{l}\text { Os novos parâmetros curriculares das escolas } \\
\text { brasileiras e educação sexual: uma proposta } \\
\text { de intervenção em Ciências }\end{array}$ & 2002 \\
\hline $\begin{array}{l}\text { Revista Ciência \& } \\
\text { Educação }\end{array}$ & $\begin{array}{l}\text { Coelho, L.; } \\
\text { Campos, L. }\end{array}$ & $\begin{array}{l}\text { Diversidade sexual e ensino de ciências: } \\
\text { buscando sentidos }\end{array}$ & 2015 \\
\hline HOLOS & $\begin{array}{l}\text { Guizzo, B.; } \\
\text { Ripoll, D. }\end{array}$ & $\begin{array}{l}\text { Gênero e sexualidade na educação básica e } \\
\text { na formação de professores: limites e } \\
\text { possibilidades }\end{array}$ & 2015 \\
\hline $\begin{array}{l}\text { Alexandria: Revista de } \\
\text { Educação em Ciência e } \\
\text { Tecnologia }\end{array}$ & $\begin{array}{l}\text { Lima, } \mathrm{A} ; \\
\text { Siqueira, } \mathrm{V} \text {. }\end{array}$ & $\begin{array}{l}\text { Ensino de Gênero e Sexualidade: diálogo com } \\
\text { a perspectiva de currículo CTS }\end{array}$ & 2013 \\
\hline $\begin{array}{l}\text { Revista Electrónica de } \\
\text { Enseñanza de las Ciencias }\end{array}$ & $\begin{array}{l}\text { Barros, S.; } \\
\text { Ribeiro, P. }\end{array}$ & $\begin{array}{l}\text { Educação para a sexualidade: uma questão } \\
\text { transversal ou disciplinar no currículo } \\
\text { escolar? }\end{array}$ & 2012 \\
\hline $\begin{array}{l}\text { Revista Latinoamericana } \\
\text { de Ciencias Sociales Niñez } \\
\text { y Juventud }\end{array}$ & Giraldo-Gil, E. & $\begin{array}{l}\text { Revisando las Prácticas Educativas: una } \\
\text { Mirada } \\
\text { Posmoderna a la Relación Género-Currículo }\end{array}$ & 2014 \\
\hline $\begin{array}{l}\text { Revista Tecné, Episteme y } \\
\text { Didaxis: TED. }\end{array}$ & $\begin{array}{l}\text { Santos, F.; } \\
\text { Souza, M. }\end{array}$ & $\begin{array}{l}\text { Corpo, gênero e sexualidade na escola: sob } \\
\text { um fio de malabarismo em sala de aula }\end{array}$ & 2014 \\
\hline
\end{tabular}

Fonte: autores.

A análise dos textos por meio da ATD permitiu a construção de unidades de sentido, as quais puderam ser organizadas em 7 categorias iniciais, e orientaram a construção de 4 categorias finais. 


\section{DIVERSIDADE SEXUAL E DE GÊNERO NAS PRODUÇÕES VOLTADAS AO ENSINO DE CIÊNCIAS DA NATUREZA}

Nesta seção serão apresentadas e discutidas as categorias finais do primeiro corpus de pesquisa e suas unidades criadas a partir do processo analítico dos textos encontrados no Portal de Periódicos da CAPES/MEC, seguindo a proposta metodológica anteriormente apresentada. Os artigos selecionados foram minuciosamente analisados e unitarizados, movimento que orientou a criação das seguintes categorias finais: gênero e sexualidade abordados somente como questão biológica; obstáculos no ensino de temáticas relacionadas à Diversidade Sexual e de Gênero; Sexismo e Educação; relações de discurso e poder desenvolvidas para e na escola.

A primeira categoria é composta por unidades de significado que discutem e expõem concepções que relacionam a Diversidade Sexual e de Gênero no conteúdo de Ciências apresentado nas escolas, com a temática envolvendo anatomia humana e propriedades morfológicas e fisiológicas do corpo. As características encontradas nas interpretações dos discursos que compõem a categoria obstáculos no ensino de temáticas relacionadas à Diversidade Sexual e de Gênero evidenciaram a questão central como sendo o direcionamento dos debates acerca do tema gênero e orientação sexual aos/às professores/professoras de Ciências da Natureza, além de enunciarem a dificuldade de apresentar e discutir conceitos relacionados ao assunto. A conexão entre Diversidade Sexual e de Gênero foi identificada na análise das unidades e na criação da categoria chamada Sexismo e Educação, levando à reflexão e avaliação crítica de movimentos discriminatórios e preconceituosos, tanto em ambientes escolares, como na sociedade mundial. Já a última categoria explora a base dos discursos encontrados nesta e nas categorias anteriores, que englobam relações de poder, controle social e de regras culturais, e historicidade da sociedade, tendo Diversidade Sexual e de Gênero como foco temático.

\subsection{Categoria I - Gênero e sexualidade abordados somente como questão biológica}

A análise empreendida pôde evidenciar que a maioria dos materiais constituintes do corpus relacionava a temática Diversidade Sexual e de Gênero na escola com o(a) professor(a) de Ciências da Natureza. Preferencialmente, docentes desta área tendem a discutir assuntos referentes à sexualidade e questões de gênero, pois há um vínculo do conteúdo com a Educação Sexual, tanto em parte anatômica humana, quanto em levantamentos sobre reprodução.

Quando uma questão sobre gênero, identidade de gênero, sexo ou orientação sexual é levantada em sala de aula, os textos analisados encaminham que o desconforto é imediato e evidente, seja a pergunta feita pelo/pela professor/professora aos alunos(as), ou o contrário, como mostra um fragmento da fala de uma professora na unidade U9II: "A gente começou a entrar por reprodução, porque entra, também, no tema 'Sexualidade', eles se fecham. Eles não gostam. Pelo menos assim, a experiência que eu tenho. Eles não gostam de falar do tema abertamente". A falta de confiança e abertura para discutir esta temática, como já evidenciado, causa um enorme silêncio na sala, um desvio de assunto ou, na pior das hipóteses, a apresentação de informações de cunho discriminatório ou preconceituoso para indivíduos que buscam referência e conhecimento. Logo, por serem pontos diretamente ligados ao corpo humano e à maneira como ele se expressa, a fonte para obtenção e compressão dos dados tende a ser associada a um professor ou uma professora de Ciências, uma vez que estes obtêm formação na área em que se estuda estruturas anatômicas e fisiológicas, já que, conforme se observa nas produções, há casos em que 
A maior parte dos alunos [...] disse nunca ter discutido na escola sobre diversidade sexual. As falas indicam, que os alunos reconhecem a necessidade de que o tema seja abordado na escola, e, segundo eles, a discussão, provavelmente, ocorreria na disciplina de Ciências, por ser uma matéria que inclui corpo humano e reprodução (U11GI).

Entretanto, é importante reconhecer que questões sociais deveriam ser, e por vezes são discutidas por educadores de diversas áreas em instituições de ensino, como Pessoa, dá o exemplo do campo de licenciados em sociologia, em que

[...] o professor(a) de sociologia deve estar atento a esta realidade, fazendo discussões que extrapolem uma visão biologizada das sexualidades e dos gêneros, desnaturalizando estes conceitos e demonstrando que somos sujeitos pertencentes a um espaço e uma realidade social, que fabrica normas, verdades e colocam limites para viver estas características humanas (Pessoa, 2012, p. 45).

Ou seja, a ideia e a compreensão de que argumentos relacionados à temática Diversidade Sexual e de Gênero são construções sociais - e portanto não limitadas a uma disciplina - é insuficientemente divulgada em nossa cultura, como evidente na unidade U12GI, que diz que o ensino de Ciências é frequentemente "o único momento em que ocorrem ações voltadas ao debate da sexualidade na escola, e nele continua a ser apresentado um corpo e uma sexualidade desconectados de questões históricas e sociais."

Ainda quando apresentada a temática sexualidade aos alunos e alunas em sala de aula, volta-se a discussão, exclusivamente, ao campo biológico, pois o foco da discussão se limita à Educação Sexual direcionada à saúde e à prevenção, tanto de Infecções Sexualmente Transmissíveis (ISTs), quanto de gravidez precoce ou indesejada, sendo possível evidenciar que nas escolas as orientações "na área da sexualidade nunca são focadas para a Diversidade Sexual. É só pra gravidez na adolescência, têm os projetos lá de prevenção de gravidez, de prevenção de doença" (U14GI). Segundo Lionço e Diniz (2009, p. 54), "Assim consideradas, tais medidas não atravessam a experiência de desejo e prazer na relação sexual como vivência afetiva e social, que supera a dimensão biológica do sexo e suas consequências".

Esses elementos são encontrados também em discursos existentes, mas não evidentes para grande parte de indivíduos que não possuem a informação e o conhecimento necessário para identificar a massiva ação de uma ideia hetoronormativa, como evidenciado em falas de professores e de professoras de Ciências da Natureza e pesquisados na área científica: "a escola não quer falar sobre esse assunto por medo dois pais..."(U5DII); "...a emoção que experimentei foi de medo de tomar posicionamento, então me calei."(U8DIV); "as significações sobre sexualidade atendem a interesses da classe dominante..." (U5GIV); "...a força de uma imagem mostrando um casal homossexual e feliz é intolerável dentro do ambiente escolar." (U6HIV); "...os conhecimentos estão organizados de forma rígida e hierárquica no currículo escolar..." (U1JIV). Mais preocupante que essa restrição à fala desses temas é a associação exclusiva de sua ocorrência na disciplina escolar de Biologia, como se tais questões não percorressem outros aspectos da vida e de estudos disciplinares. É possível assumir que as barreiras em falas como as acima citadas são apenas reforçadas por essa compartimentalização biológica da temática Diversidade Sexual e de Gênero, uma vez que quanto menos e poucos espaços falam de algo, mais a capacidade de controle e menores os impactos desse algo.

Sendo assim, a necessidade de se produzir materiais adequados com referência atualizada é reconhecida por alguns professores e algumas professoras, mas a acessibilidade para tais objetos de 
trabalho e de estudo pode ser a barreira que impede o alcance destas informações, como evidenciado na unidade U2FI, que indica que os docentes, ocasionalmente, percebem a necessidade de se aderir à expressões mais abertas quando se discute Diversidade Sexual e de Gênero na escola, porém, não dispõem de "subsídios adequados para trabalhar essas questões" (U2FI). Segundo Junqueira, as escolas

[...] precisariam ser acompanhados de uma permanente discussão dos conteúdos curriculares e das formas de ensinar, aprender e conviver. Não menos importantes seriam os esforços para garantir maior autonomia ao espaço escolar em relação a outros campos privados de formação, bem como para construir uma escola mais democrática (JUNQUEIRA 2009, p. 178).

Metodologias diferenciadas e apropriadas para o momento histórico atual, que visem a exposição do tema central desta pesquisa em sala de aula, como exemplo a utilização de imagens com casais e/ou famílias homoafetivas, dependem do interesse de educadores/as, como também da existência de instrumentos de auxílio e orientação para aqueles que se mostram dispostos a pesquisar e aprimorar seus conhecimentos sobre o tema, desconstruindo valores de cunho preconceituoso ou discriminatórios e conduzindo seu trabalho como professor/a à novas investigações, visando aperfeiçoar sua prática docente. Todavia, isso não é suficiente enquanto sistematicamente os "legitimados" a falar sobre esse tema forem poucos e não se expandirem as bases da discussão para outros níveis do conhecimento, como o ético, o sociológico, o econômico, etc.

\subsection{Categoria II - Obstáculos no ensino de temáticas relacionadas à Diversidade Sexual e de Gênero}

Para educadores e educadoras, até mesmo da área da Ciências da Natureza, expor e discutir questões sociais, tais como Diversidade Sexual e de Gênero, pode ser um exercício complexo (ABREU, 2017; BONFIM, 2009; RODRIGUES; SALLES, 2011; PETRENAS; GONINI; MOKWA, 2014). A imposição de valores heteronormativos e de natureza machista trabalhados em sala de aula pelos/as licenciados/as está fortemente presente na escola, tanto no conteúdo a ser estudado a partir do currículo da escola (cuja construção histórica abrange ideologias tradicionais), quanto no ambiente familiar dos/das estudantes (que resulta no receio de professores e professoras em discutir temáticas ligadas à gênero e Diversidade Sexual, principalmente por medo de reclamações que possam surgir por parte de responsáveis pelos/pelas estudantes).

Apresentar e discutir assuntos que demandam conhecimento sócio-histórico-cultural, posicionamento político (não-partidário) e desconstrução de pensamentos, é uma tarefa complicada para professores e professoras, como pode-se evidenciar em grande parte das unidades que compõem esta categoria. A título de exemplo, isso se mostra nitidamente quando uma professora relata com convicção de que a escola não quer falar sobre Diversidade Sexual e de Gênero por medo das reações que os pais teriam se soubessem que seus filhos estão aprendendo sobre o assunto. Logo, uma pergunta foi proposta aos entrevistados da pesquisa analisada: "a escola tem medo dos pais ou não se sente capacitada para isso"? Um dos participantes apontou que "a escola não tem formação para discutir esses assuntos, mas que muitos pais também não querem que a escola fale sobre o mesmo" (U5DII).

Mesmo quando a escola percebe a necessidade de apresentar e discutir concepções sobre identidade de gênero, sexo biológico, orientação sexual e expressão de gênero e toma as devidas precauções para o desenvolvimento do conhecimento, ou seja, indaga o interesse dos/das estudantes acerca da temática, comunica a equipe diretiva da instituição e consulta os pais por meio de recados que 
expressam a motivação e os objetivos da discussão. A fala de uma professora mostra que "há pais, mães e responsáveis que se contrapõem a ele, tanto que não permitem a participação de seus filhos em determinadas atividades" (U2HII). De mesmo modo, pode-se afirmar a aversão a questões relacionadas à Diversidade Sexual e de Gênero por parte dos/das responsáveis pelos alunos e pelas alunas. Tal compreensão fica evidente na fala de professoras ao lamentarem que:

[...] dos 47 alunos que frequentam as duas turmas de $5^{\circ}$ anos, apenas 25 compareceram no dia em que foi apresentada e discutida a temática na escola, tal ato foi justificado pelo fato de que "quase metade deles não teve autorização para participar da atividade" (U4HII).

Porém, quando um assunto relacionado a gênero e/ou sexualidade é solicitado pelo/pela docente ou por alunos e alunas, a responsabilidade de debater a temática é direcionada para professores e professoras de Ciências da Natureza, como visto na unidade anterior, que mostra o reconhecimento, por parte de discentes, da necessidade de abordar o tema na escola, e que a discussão, "[...] provavelmente, ocorreria na disciplina de Ciências, por ser uma matéria que inclui corpo humano e reprodução" (U11GI). Para desenvolver conhecimento escolar a partir das concepções dos/das alunos/as com o auxílio da ciência acadêmica, a bagagem pedagógica, didática e sócio-históricocultural durante a graduação do licenciando não se mostra suficiente para realizar uma discussão desconstruída e livre de conceitos pré-estabelecidos. Como exemplo, cabe a observação que uma aluna do curso de Licenciatura em Biologia faz por não se sentir segura em realizar a discussão cuja responsabilidade lhe é atribuída: "[...] eu não recebi formação, apenas algumas informações; a sexualidade é além de informação, tem coisas que eu não sei como lidar" (U4DII).

A falta de conhecimento sobre Diversidade Sexual e de Gênero durante o curso de licenciatura se repete em outras unidades de significado. Esta carência é exibida nas falas de discentes que evidenciam a recepção de orientação para trabalhar a temática em forma de palestras, oficinas e minicursos em projetos do Programa Institucional de Bolsas de Iniciação à Docência (PIBID). Todos afirmaram que "[...] não se sentem preparados para esta tarefa[...]". Isso também é evidenciado na observação de um/uma estudante, ao comentar que "[...] sente falta de maiores conhecimentos sobre o tema" (U2DII). Além dessas perspectivas, a unidade U3LII aponta que, para agravar mais a situação,

[...] os/as docentes recebem pouca ou nenhuma formação em assuntos de gênero e diversidade, e creem que estes não existem ou são impossíveis de modificar, nem consideram estes assuntos como um critério para selecionar materiais de aprendizagem e construir o currículo (U3LII).

A importância da presença de conteúdos sobre gênero e sexualidade na formação de professores e professoras é inquestionável, como aponta Lopes,

é necessário se despir de preconceitos para fazer uma educação cada vez mais humana, aberta às experiências múltiplas. Por isso, deve-se investigar a base da opressão, conhecê-la para que através da reflexão crítica e da prática educativa possamos contribuir na sua superação, discutindo a diversidade e o seu convívio, e fazendo emergir as contradições provenientes da realidade. Pois, essa tem sido uma prerrogativa daqueles educadores (as) que não se conformam com a realidade dada e fazem da sua prática pedagógica um instrumento de reconhecimento das diferenças e de luta por igualdade (LOPES 2017, p. 3).

Porém, a desconstrução de ideias socioculturais é um exercício fundamental para a apropriação de termos e ações que não sejam discriminatórios, principalmente para acrescentar conhecimento acerca 
deste tema àqueles que têm interesse, mas não possuíram instruções durante sua formação. Educadores e educadoras que carregam preconceitos e não conseguem perceber e/ou problematizar estas concepções, "[...] promoverão a manutenção de práticas e discursos que descriminam, excluem e diminuem LGBT no ambiente escolar" (U13GII), pois, mesmo se forem ofertados conhecimentos acadêmicos sobre Diversidade Sexual e de Gênero, ainda assim, durante a prática, "docentes [...] têm dificuldades em ensinar sobre sexualidade e muitos não se sentem à vontade para debater sobre estas questões com seus discentes em virtude dos seus valores socioculturais, sobretudo os de cunho religioso" (U2BII).

Tais apontamentos evidenciam não apenas obstáculos para a discussão, mas também a manutenção de deficiências da própria discussão no que tange à diversidade e respeito ao coletivo. Por exemplo, a discussão da Diversidade Sexual, quando presente, mostra-se, reiteradamente, associada ao sistema reprodutor feminino e/ou às infecções sexualmente transmissíveis (ISTs). A fala de um aluno, que perguntou à professora, durante o ensino de ISTs: "Mas professora, o homossexual é mesmo um grupo de risco? Ele pega mais AIDS? Tem alguma coisa nele que faz pegar mais a doença do que outros?" (U9II), coloca presente a necessária discussão que tem de se ter do tema, assim como aponta que a carência de material de apoio ao professor e à professora que contenham informações remodeladas ao momento histórico atual em relação à Diversidade Sexual e de Gênero deve ser suprida.

Outras unidades também apresentaram relatos parecidos, focando nesta relação entre gênero e orientação sexual e infecções sexualmente transmissíveis, dando maior relevância ao "...estabelecimento de uma 'normalidade' da conduta sexual e para o tratamento das questões vinculadas à saúde e à doença" (U1FI); nas aulas de ciências cujo conteúdo é anatomia humana, o foco é discutir gravidez precoce e prevenção de ISTs, "...enquanto as questões ligadas ao sexo como fonte de prazer e à discriminação por gênero e orientação sexual continuaram à margem do currículo" (U1BI); como o relato de que a temática sexualidade, "...quando abordada na escola, de um modo geral, é reduzida às questões ligadas à biologia e à reprodução" (U7GI). E mesmo que haja uma abordagem transversal de Educação Sexual, ainda é realizada de maneira exclusivamente biológica, "...em diálogo mais restrito com uma literatura oriunda da saúde reprodutiva, em que o estudo do corpo é delegado ao campo da biologia" (U1II). Assim, conforme Weeks:

[...] produz-se uma fusão entre duas teorias, plausíveis, embora não demonstradas: que haja uma afinidade eletiva entre algumas enfermidades e certas práticas sexuais; e que certas práticas sexuais são a causa de algumas enfermidades. E uma terceira: a saber, que certas práticas sexuais são enfermidades (WEEKS 1985, p. 86).

Isto é, fundem-se e se confundem elementos distintos em relações criadas a partir da historicidade difamatória de LGBTs, como relata Louro:

A negação dos/as homossexuais no espaço legitimado da sala de aula acaba por confiná-los às "gozações" e aos "insultos [...], fazendo com que, deste modo, jovens gays e lésbicas só possam se reconhecer como desviantes, indesejáveis ou ridículos (LOURO, 2003, p. 68).

Grande parte das considerações observadas na construção desta categoria são de interpretação negativa em relação à discussão de questões de Diversidade Sexual e de Gênero nas escolas. Porém, encontram-se unidades de significado, neste mesmo grupo, que buscam alternativas e mudanças na educação; que relatam, por exemplo, a percepção que um/uma professor/professora teve de que a prática, considerada por ele/ela e pelos/as alunos/as como desagradável, por expor a temática em 
sala de aula "estava de fato sendo desestabilizadora, provocando-os, tirando-os de um possível lugar tranquilo, fazendo-os pensar" (U14MII). A exposição de questões sociais no ensino básico (e superior) é fundamental para a construção crítica do/da estudante; é quando há o encontro de ideias, até mesmo inexploradas, que ocasionam o questionamento sobre a efetividade de suas teorias. Logo, o processo de desconstrução de conceitos e pré-conceitos é fundamental em discussões sobre gênero e sexualidade, pois "[...] si podemos ver a través de estos mensajes, nos podemos revelar en contra de ellos [...], y abrir otras posibilidades" (U7LII).

\subsection{Categoria III - Sexismo e educação²}

A necessidade de se apresentar, discutir e diferenciar temáticas relacionadas à Diversidade Sexual e de Gênero em sala de aula é vista e reconhecida por educadores/as e pesquisadores/as (BORTOLINI, 2011; GUIZZO, 2018; RODRIGUES, 2017; SOLARO, 2015), como foi constatado em unidades mencionadas nas categorias anteriores. Segundo o Dicionário Online de Português ${ }^{3}$, a palavra gênero tem como um dos significados: diferença entre homens e mulheres que, construída socialmente, pode variar segundo a cultura, determinando o papel social atribuído ao homem e à mulher e às suas identidades sexuais; já a palavra sexo é descrita como a "reunião das características distintivas que, presentes nos animais, nas plantas e nos seres humanos, diferenciam o sistema reprodutor; sexo feminino e sexo masculino"4. O discurso que Louro (2003, p.21, grifo da autora) utiliza em seu trabalho, evidencia os sentidos e as significações anteriores: "seja no âmbito do senso comum, seja revestido por uma linguagem 'científica', a distinção biológica, ou melhor, a distinção sexual, serve para compreender - e justificar - a desigualdade social".

A diferenciação entre gênero e sexo é frequentemente desconhecida ou ignorada. Aspirando "rejeitar um determinismo biológico implícito no uso de termos como sexo ou diferença sexual" (Scott, 1995, p. 72), as feministas anglo-saxãs passaram a usar a palavra gender como distinta de sex, com o intuito de evidenciar, por meio de expressões, "o caráter, fundamentalmente, social das distinções baseadas no sexo" (Scott, 1995, p. 72).

Isso, na unidade U7AIII foi observado que:

[...] olhando-se para o binômio homem e mulher sob a visão de construção social pode-se visualizar o simbolismo presente em vestimentas, comportamentos e outros, que ao serem socialmente distintos para homens e mulheres, pressupõem o sexo como forma de poder para o gênero masculino e submissão do feminino (U7AIII).

Aponta-se, aí, o poder e o discurso sendo utilizados da forma mais conveniente para um grupo, desqualificando outros em termos das características em questão, e então, apresentando a necessidade do sexo biológico determinar o gênero, ou seja, determinar a maneira como a pessoa deve se portar perante a sociedade, tal definição podendo fazer-se de forma ameaçadora.

Logo, pela análise se evidencia que os corpos estão em constante vigilância e qualquer exceção à norma exigida pode gerar descontentamento da comunidade em que o indivíduo se encontra, seja familiar, escolar, profissional, ou mesmo fora destes. Contudo, em instituições educacionais pode-se

\footnotetext{
${ }^{2} \mathrm{O}$ texto referente a esta categoria foi submetido e apresentado no IX Encontro Regional Sul de Ensino de Biologia (EREBIO-SUL), será publicado em Anais do evento.

${ }^{3}$ https://www.dicio.com.br/genero/

${ }^{4}$ https://www.dicio.com.br/sexo/
} 
observar com clareza a separação entre grupos, principalmente relacionados ao gênero dos/das estudantes, divisões estas estabelecidas e instruídas pela própria escola.

Diferenças, distinções, desigualdades [...]. A escola entende disso. Na verdade, a escola produz isso. Desde seus inícios, a instituição escolar exerceu uma ação distintiva. Ela se incumbiu de separar os sujeitos - tornando aqueles que nela entravam distintos dos outros, os que a ela não tinham acesso. Ela dividiu também, internamente, os que lá estavam, através de múltiplos mecanismos de classificação, ordenamento, hierarquização (LOURO, 2003, p. 57).

Como evidenciado na unidade U11CIII, "[...] não são apenas as mulheres que sofrem com o machismo presente em nossa sociedade, os próprios homens são colocados em um esquema de afirmação da masculinidade a todo momento". Meninos são postos em situações de afirmação e legitimação de seu gênero, frequentemente, principalmente na escola, onde até mesmo o Livro Didático apresenta a maneira que eles têm que se portar e vestir, os brinquedos aos quais eles devem brincar, o que eles devem gostar e não gostar. Qualquer aproximação a deveres, características e expressões ditas do gênero oposto, podem causar desconforto às pessoas ao redor do indivíduo, que corrigem as atitudes e ressaltam a maneira correta que um menino deve se portar socialmente, conduzindo, assim, os modos de exercício de sua liberdade de expressão e autonomia. A unidade U6EIII deixa bem claro tal ideia, expressando que:

[...] o poder do homem é, então, entendido - bem apontou Ramirez (1989) - como respeitabilidade, autoridade, invulnerabilidade, força. Desse modo, no modelo de masculinidade a ser seguido nos livros, destacam-se as ideias de que o homem de verdade é solitário, reservado e prático, voltado para agir e realizar atividades [U6EIII].

Tais noções vão ao encontro da unidade U12CII, a qual expõe que desta maneira sujeitos do gênero masculino são, constantemente, vigiados e avaliados para confirmarem e validarem, frequentemente, sua orientação sexual como a heterossexual, procurando, assim, a aprovação de outros homens a respeito de suas maneiras de se portar socialmente. O não entendimento de tais circunstâncias e a não aceitação leva ao pré-conceito e à discriminação do sujeito por parte de quem o observa, podendo ocasionar atitudes psicologicamente e fisicamente violentas.

Portanto, os hábitos, frequentemente, comuns, as práticas e os argumentos banalizados necessitam se transformar em metas de atenção e concentração renovadas, de indagação e, principalmente, de suspeita e desconfiança. Como Louro, comenta em seu trabalho:

É necessário demonstrar que não são propriamente as características sexuais, mas é a forma como essas características são representadas ou valorizadas, aquilo que se diz ou se pensa sobre elas que vai construir, efetivamente, o que é feminino ou masculino em uma dada sociedade e em um dado momento histórico (LOURO, 2003, p. 21)

Sendo assim, é provável que a tarefa imediata seja a de não confiar no que é tomado e transpassado como "normal", e até mesmo "natural", mantendo relações abertas para novos conhecimentos, dando liberdade de expressão sem o viés da avaliação sexual, percebendo a discriminação em falas próprias e livrando-se do preconceito carregado historicamente. 


\subsection{Categoria IV - Relações de discurso e poder desenvolvidas para e na escola}

As discussões das categorias anteriores foram baseadas em relações de discurso e poder. Estes, intimamente interligados e dependentes, formam a base do controle social, das regras culturais e da construção histórica da sociedade de diversas formas, como exemplo, citando Foucault:

O discurso veicula e produz poder; reforça-o mas também o mina, expõe, debilita e permite barrá-lo. Da mesma forma, o silêncio e o segredo dão guarida ao poder, fixam suas interdições; mas também, afrouxam seus laços e dão margem a tolerâncias mais ou menos obscuras (FOUCAULT, 1988, p.96; apud Louro, 2003, p. 43).

Consequentemente, quando se fala em gênero, identidade de gênero, sexo biológico, orientação sexual e expressões de gênero, estão sendo expostos fundamentos sócio-históricos-culturais da construção da sexualidade humana.

Introduzir a temática em instituições formais de ensino é uma tarefa complexa, visto que a escola tem seus discursos próprios e suas respectivas redes de poder. Um exemplo disto é a separação e o favorecimento de disciplinas curriculares, característica que faz com que as escolas sejam conceituadas "como mecanismos de compartimentalização de saberes [...], organizados de forma rígida e hierárquica [...], onde cada conteúdo/temática deve estar delimitado em uma determinada disciplina curricular" (U1JIV).

Ao possuir suas próprias regras de convivência social, a escola determina um modelo para a seleção dos indivíduos, priorizando e privilegiando aqueles que se encaixam nos padrões estabelecidos pela instituição. Este movimento de imposição nem sempre é planejado ou intencional; são concepções e ações involuntárias para os que reproduzem os princípios. Os resultados das ações podem definir o modelo ideal de professores e professoras, alunos e alunas, e de funcionários/as que fazem parte daquela organização, pois são grupos sociais e, por isso, foram e são objetos de representações. Como exemplo disto, basta perceber a tendência de diferenciação existente dentro da educação "entre homens e mulheres nas trajetórias escolares; os homens dirigindo-se às áreas das ciências exatas e engenharias e as mulheres às ciências humanas, letras e artes" (U5EIV).

Assim, ao longo do tempo, alinham-se determinadas características, apelam-se para alguns recursos para falar deles e delas. Essas representações não são, contudo, meras descrições que "refletem" as práticas desses sujeitos; elas são, de fato, descrições que os "constituem", que os "produzem". Estamos aqui operando a partir de uma perspectiva teórica que entende a representação não como um reflexo ou espelho da realidade, mas como sua constituidora (LOURO, 2003, p. 99).

Discussões sobre Diversidade Sexual e de Gênero também estão expostas nos meios digitais, como pode-se constatar na fala de alunos e alunas entrevistados/as para a construção de um artigo em que, quando interrogados sobre a aprendizagem que obtinham sobre o assunto, "a maioria indicou a mídia como principal fonte, sendo a segunda fonte mais indicada, o professor" (U10GIV).

Partindo da ideia de que, acreditamos neste trabalho, que cabe à escola informar, educar e proporcionar conhecimento, adaptando-se às inovações, conforme as ciências vão sendo desenvolvidas, é possível perceber a instituição formal de ensino ainda como "um ambiente historicamente disciplinador e normativo que tem como referência a heteronormatividade, desconsiderando o caráter construído das identidades" (U8IIV), cada vez mais manifestadas e complexas. Segundo Louro (2003), é "[...] preciso admitir um jogo complexo e instável em que o 
discurso pode ser, ao mesmo tempo, instrumento e efeito de poder, e também obstáculo, escora, ponto de resistência e ponto de partida de uma estratégia oposta".

Os significados que deixam de ser atribuídos, formalmente, à Diversidade Sexual e de Gênero são, então, pressupostos ou estabelecidos apenas a partir dos conceitos utilizados no convívio familiar, que pode carregar preconceitos, e, desta maneira:

Criam-se visões patologizantes que se transformam em significados compartilhados socialmente, entendendo que os desvios e perversões devem ser evitados, marginalizados e excluídos, enquanto existe um padrão sexualmente 'correto' que deve ser seguido (U4GIV).

O objetivo que se tenta alcançar, então, é a problematização da forma organizacional da escola como instituição, visto que não tem alcançado respostas às particularidades dos sujeitos que a compõem, tornando-se inadiável a incorporação de debates sobre os princípios e as práticas de um método de inclusão social "que garanta o acesso e considere a diversidade humana, social, cultural, econômica dos grupos historicamente excluídos" (U10AIV). Assim, é importante a prática do exercício de reflexão acerca da educação, do conhecimento e do processo de ensino e aprendizagem que há nas escolas, na maneira como está organizada e que ocorreu esta organização histórica e socialmente, como está vinculado a certas redes de poder e como ocorreu sua modificação neste período, "sendo feita uma contextualização que leve em conta a situação de vida do/a aluno/a, analisando a forma como aquele conhecimento estrutura-se no presente" (U11IIV).

Portanto, o processo de mudança e adaptação deve começar com o preparo e a escolha dos materiais de ensino e de aprendizagem, pois, "o currículo, adequadamente construído, deve atender às necessidades dos alunos e professores de compreender a sociedade na qual vivem" (U5FIV), e auxiliar na comunicabilidade entre educadores/educadoras e estudantes sobre temáticas sócio-históricoculturais e assuntos do momento histórico em que se encontram. Assim, o foco no investimento e na conquista educacional deve estar, essencialmente, na aplicação das habilidades e no desenvolvimento da tolerância através da inclusão de interesses coletivos, como exemplo a reciprocidade, a solidariedade, a consciência de compromisso social e, principalmente, o respeito ao próximo.

\section{CONSIDERAÇÕES FINAIS}

Com base na análise do primeiro corpus de pesquisa, pode-se constatar que a temática Diversidade Sexual e de Gênero na Educação Básica é apresentada por docentes da área de Ciências, como afirma a Base Nacional Comum Curricular (BNCC) de 2017. Observou-se que educadores e educadoras trabalham questões relacionados às propriedades anatômicas, morfológicas e fisiológicas do corpo humano, mas têm dificuldades em discutir questões como orientação sexual e identidade de gênero em sala de aula, tanto por questões religiosas da comunidade escolar, quanto por preocupação com a interpretação que os/as responsáveis pelos/pelas estudantes terão sobre o tema.

Constatou-se que movimentos preconceituosos e discriminatórios em relação a gênero/identidade de gênero ou a orientação sexual apresentam-se associados a princípios sexistas, existentes, ainda, na sociedade atual, e portanto, no ambiente escolar. A fundamentação teórica que originou as questões já apresentadas sobre Diversidade Sexual e de Gênero foi verificada no momento de análise de discursos encontrados em todo o corpus. Os discursos demonstraram que as relações de poder constroem a forma das regras culturais e do controle social, moldando, assim, a historicidade social, conforme a prevalência do item de que se trata. 
Sendo assim, há a necessidade de se exercitar a percepção de termos inapropriados, ofensivos ou opressores em discursos próprios ou enunciados por outros indivíduos, principalmente no papel de educador/educadora, pois tal exercício pode ajudar na desconstrução de conceitos pré-estabelecidos, manifestações intolerantes e atos discriminatórios no ambiente escolar, e, com isso, disseminar e promover o respeito às diferenças de cada ser humano.

\section{REFERÊNCIAS}

ABREU, Andrezza. Educação Sexual e a Formação de Professores: uma proposta para a formação inicial dos licenciados em ciências naturais. 2017. 64p. Dissertação (Mestre em Ensino de Ciências) - Universidade de Brasília, Brasília.

BARROS, Suzana. RIBEIRO, Paula Regina. Educação para a sexualidade: uma questão transversal ou disciplinar no currículo escolar? Revista Electrónica de Enseñanza de las Ciencias, v. 11, n. 1, 2012. ISSN: 1579-1513. Disponível em:

http://reec.uvigo.es/volumenes/volumen11/REEC 11119 ex570.pdf . Acesso: 2020.

BONFIM, Claudia. Educação sexual e formação de professores de ciências biológicas: contradições, limites e possibilidades. 2009. 267p. Tese (Doutora em Educação) Universidade Estadual de Campinas, Campinas.

BORRILLO, Danilo. Homofobia \& Educação: um desafio ao silêncio. Brasília. LetrasLivres. 2009.

BORTOLINI, Alexandre. Diversidade sexual e de gênero na escola. Revista Espaço Acadêmico. Maringá, n. 123, Agosto. 2011. ISSN: 1519-6186. Disponível em:

http://www.periodicos.uem.br/ojs/index.php/EspacoAcademico. Acesso em: 2019.

BRASIL. Base Nacional Comum Curricular. Brasília: MEC, 2017. Disponível em:

http://portal.mec.gov.br/index.php?option=com docman\&view=download\&alias=79601-anexotexto-bncc-reexportado-pdf-2\&category slug=dezembro-2017-pdf\&Itemid=30192. Acesso em: 2019.

COELHO, Leandro. CAMPOS, Luciana Maria. Diversidade sexual e ensino de ciências: buscando sentidos. Ciência \& Educação. v. 21, n. 3, Outubro-Dezembro. 2015. ISSN: 1980-850x. Disponível em: http://www.scielo.br/scielo.php?script=sci arttext\&pid=S1516-

73132015000400007\&lng=pt\&tlng=pt. Acesso: 2020.

COLLING, Leandro. A igualdade não faz o meu gênero - Em defesa das políticas das diferenças para o respeito à diversidade sexual e de gênero no Brasil. Contemporânea. v. 3, n. 2, JulhoDezembro. 2013. ISSN: 2236-532x. Disponível em:

http://www.contemporanea.ufscar.br/index.php/contemporanea/article/view/149. Acesso: 2020.

GIRALDO-GIL, Elida. Revisando las Prácticas Educativas: una Mirada Posmoderna a la Relación Género-Currículo. Revista Latinoamericana de Ciencias Sociales, Niñez y Juventud, v. 12, n. 1, Março, 2014. ISSN: 2027-7679. Disponível em: http://revistaumanizales.cinde.org.co/rlcsnj/index.php/RevistaLatinoamericana/article/view/1122/488. Acesso: 2020.

GUIZZO, Bianca. Corpo, gênero e sexualidade: articulações possíveis entre trabalhos acadêmicos e escola. Revista Ensino de Ciências e Humanidades. Humaitá. v. II, n. 2, Julho-Dezembro. 2018. ISSN: 2594-8806. Disponível em: http://www.periodicos.ufam.edu.br/rech. Acesso em: 2019. 
GUIZZO, Bianca. RIPOLL, Daniela. Gênero e Sexualidade na Educação Básica e na Formação de Professores: limites e possibilidades. HOLOS, v. 6. 2015. ISSN: 1807-1600. Disponível em: http://www2.ifrn.edu.br/ojs/index.php/HOLOS/article/view/2945/1243. Acesso 2020.

JUNQUEIRA, Rogério. Homofobia \& Educação: um desafio ao silêncio. Brasília. LetrasLivres. 2009.

LIMA, Ana Cristina. SIQUEIRA, Vera Helena. Ensino de Gênero e Sexualidade: diálogo com a perspectiva de currículo CTS. Revista de Educação em Ciência e Tecnologia ALEXANDRIA, v. 6, n. 3, Novembro, 2013. ISSN: 1982-5153. Disponível em: https://periodicos.ufsc.br/index.php/alexandria/article/view/38022/29022. Acesso: 2020.

LIONÇO, Tatiana. DINIZ, Débora. Homofobia \& Educação: um desafio ao silêncio. Brasília. LetrasLivres. 2009.

LOPES, Beliza. O Ensino de Gênero e Sexualidade na Formação de Professores. Seminário Internacional Fazendo Gênero 11 \& 13th Women's Worlds Congress (Anais Eletrônicos), Florianópolis, 2017, ISSN: 2179-510X. Disponível em: http://www.en.wwc2017.eventos.dype.com.br/resources/anais/1497836421 ARQUIVO FazendoGe nerorevisado.pdf. Acesso: 2020.

LOURO, Guacira. Gênero, sexualidade e educação: uma perspectiva pós-estruturalista. 6 ed. Rio de Janeiro: Petrópolis. 2003.

LÜDKE, Menga. ANDRÉ, Marli. Pesquisa em educação: abordagens qualitativas. São Paulo: EPU. 1986.

MARTINES, Elizabeth. ROSSAROLLA. Sexo e Sexualidade: tabu, polêmica ou conceitos polissêmicos? Reflexões sobre/para a formação de educadores. Revista Exitus, v. 8, n 2, Maio/Agosto, 2018. ISSN: 2237-9460. Disponível em:

http://www.ufopa.edu.br/portaldeperiodicos/index.php/revistaexitus/article/view/537/348. Acesso: 2020.

MARTINS, Eliećlia. HOFFMANN, Zara. Os papéis de Gênero nos Livros Didáticos de Ciências. Ensaio Pesquisa em Educação em Ciências, v. 9, n. 1, 2007. ISSN: 1415-2150. Disponível em: https://periodicos.ufmg.br/index.php/ensaio/article/view/9975. Acesso: 2020.

MORAES, Roque. GALIAZZI, Maria. Análise textual discursiva: processo reconstrutivo de múltiplas faces. Ciência \& Educação, Bauru, v. 12, n. 1, Abril, 2006. ISSN 1980-850X. Disponível em: http://www.scielo.br/scielo.php?script=sci arttext\&pid=S1516-

73132006000100009\&lng=pt\&tlng=pt. Acesso em: 2019.

PESSOA, Emerson. Políticas Públicas, a Atuação Docente e o Desenvolvimento de Habilidades: gêneros e sexualidades na educação básica. Revista on line de Política e Gestão Educacional, n. 12, $1^{0}$ semestre, 2012. ISSN: 1519-9029. Disponível em:

https://periodicos.fclar.unesp.br/rpge/article/view/9326/6178. Acesso: 2020.

PETRENAS, Rita. GONINI, Fatima MOKWA, Valeria. A Educação Sexual no Curso de Pedagogia: um processo em construção permeado por desafios e contradições. In: ENCONTRO NACIONAL DE DIDÁTICA E PRÁTICA DE ENSINO; 2014, Fortaleza. Didática e prática de ensino na relação com a formação de professores. Fortaleza: Editora da Universidade Estadual do Ceará, 2014, v.2. p. 357-369. 
RODRIGUES, Beatriz. Diversidade sexual, gênero e inclusão escolar. Revista Brasileira de Rducação Básica. Belo Horizonte, v. 2, n. 6, Novembro-Dezembro. 2017. ISSN: 1809-449X. Disponível em: https://rbeducacaobasica.com.br/. Acesso em: 2019.

RODRIGUES, Adriana. SALLES, Gilsani. Educação Sexual, Gênero e Diversidade Sexual: formação de professoras e alunas multiplicadoras como metodologia de ensino. In: SIMPÓSIO GÊNERO E POLÍTICAS PÚBLICAS, 2, 2011, Londrina. Anais. Paraná: EDUEL, 18-19 dez. GT6 - 2.

SANTANA, Jaqueline. SANTOS, Vanessa. A inserção de conteúdos sobre identidade de gênero na escola: uma visão a partir de noções sobre conhecimento/saberes. Research, Society and Development, v. 7, n. 9, Junho, 2018. ISSN: 2525-3409. Disponível em: https://rsd.unifei.edu.br/index.php/rsd/article/view/451/341. Acesso: 2020.

SANTOS, Fernanda. SOUZA, Marcos. Corpo, gênero e sexualidade na escola: sob um fio de malabarismo em sala de aula. Reviste Tecné, Episteme y Didaxis: TED, Outubro, 2014. ISSN: 2323-0126. Disponível em:

https://revistas.pedagogica.edu.co/index.php/TED/article/view/3208/3018. Acesso: 2020.

SCOTT, Joan. Gênero: uma categoria útil de análise histórica. Educação e Realidade, v. 20, n. 2, Jul/Dez, 1995. ISSN: 2175-6236. Disponível em:

https://seer.ufrgs.br/index.php/educacaoerealidade/article/view/71721. Acesso: 2019.

SOLARO, Thaís. Sexualidade e gênero na sala de aula: abordagens didáticas e discussões. 2015. 58p. Trabalho de conclusão de curso (Graduação em Ciências Biológicas) - Universidade Federal do Rio Grande do Sul, Porto Alegre.

SOUZA, Marcos. Partilhando uma experiência de ensino sobre gênero e sexualidade em um curso de formação de professores de Ciências e Biologia. Reviste Tecné, Episteme y Didaxis: TED, Outubro, 2014. ISSN: 2323-0126. Disponível em:

https://revistas.pedagogica.edu.co/index.php/TED/article/view/3217. Acesso: 2020.

TONATTO, Suzinara. SAPIRO, Clary. Os novos parâmetros curriculares das escolas brasileiras e educação sexual: uma proposta de intervenção em ciências. Psicologia \& Sociedade, v. 14, n. 2, Jul/Dez, 2002. ISSN: 1807-0310. Disponível em: http://www.scielo.br/scielo.php?pid=S010271822002000200009\&script=sci abstract\&tlng=pt. Acesso em: 2020.

WEEKS, Jeffrey. Sexuality and its discontents: meanings, myths \& modern sexualities. Londres: Routlegde \& Kegan Paul. 1985. 